\title{
Performance analysis of Fuzzy logic based speed control of DC motor.
}

\author{
Mohammed Shoeb Mohiuddin, Mahboob Alam \\ Assistant Professor, Department of Electrical Engineering Mewar University, Chittorgarh, Rajasthan, India \\ Assistant Professor, Department of Chemical Engineering Mewar University, Chittorgarh, Rajasthan, India
}

\begin{abstract}
In this paper we have designed a separately excited DC motor whose speed can be controlled using PID and fuzzy tuned PID controller first, the fuzzy logic controller is designed according to fuzzy rules so that the systems are fundamentally robust. There are 25 fuzzy rules for self-tuning of each parameter of PID controller. The FLC has two inputs. One is the motor speed error second is change in speed error and the output of the FLC i.e. the parameters of PID controller are used to control the speed of the separately excited DC Motor. The fuzzy self-tuning approach implemented on a conventional PID structure was able to improve the dynamic as well as the static response of the system. Comparison between the conventional output and the fuzzy self-tuning output was done on the basis of the simulation result obtained by MATLAB. The simulation results demonstrate that the designed self-tuned PID controller realize a good dynamic behavior of the DC motor, a perfect speed tracking with less rise and settling time, minimum overshoot, minimum steady state error and give better performance compared to conventional PID controller.
\end{abstract}

Keywords: DC motor: Fuzzy tuned PID: Speed control

\section{INTRODUCTION}

The speed of DC motors can be adjusted within wide boundaries so that this provides easy controllability and high performance. DC motors used in many applications such as still rolling mills, electric trains, electric vehicles, electric cranes and robotic manipulators require speed controllers to perform their tasks. Speed controller of DC motors is carried out by means of voltage control in 1981 firstly by Ward Leonard

The proportional - integral - derivative (PID) controller operates the majority of the control system in the world. It has been reported that more than $95 \%$ of the controllers in the industrial process control applications are of PID type as no other controller match the simplicity, clear functionality, applicability and ease of use offered by the PID controller [3], [4]. PID controllers provide robust and reliable performance for most systems if the PID parameters are tuned properly.

The major problems in applying a conventional control algorithm (PI, PD, PID) in a speed controller are the effects of non-linearity in a DC motor. The nonlinear characteristics of a DC motor such as saturation and fiction could degrade the performance of conventional controllers [1], [2].Generally, an accurate nonlinear model of an actual DC motor is difficult to find and parameter obtained from systems identification may be only approximated values. The field of Fuzzy control has been making rapid progress in recent years. Fuzzy logic control (FLC) is one of the most successful applications of fuzzy set theory, introduced by L.A Zadeh in 1973 and applied (Mamdani 1974) in an attempt to control system that are structurally difficult to model.

\section{a. Motor model -}

\section{Proposed Algorithm}

When a separately excited motor is excited by a field current of $i_{f}$ and an armature current of $i_{a}$ flows in the circuit, the motor develops a back emf and a torque to balance the load torque at a particular speed.

The $i_{f}$ is independent of the $i_{a}$. Each windings are supplied separately. Any change in the armature current has no effect on the field current. The $\mathrm{i}_{\mathrm{f}}$ is normally much less than the $i_{\mathrm{a}}$.

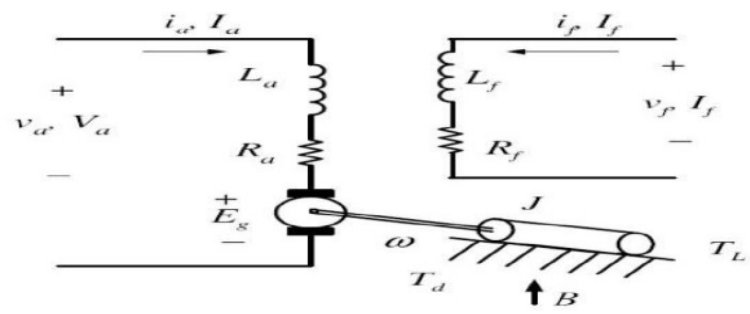

Figure1: Separately excited DC motor 
Where

$\mathrm{Va}$ is the armature voltage. (In volt)

$\mathrm{Eb}$ is back emf the motor (In volt)

Ia is the armature current (In ampere)

$\mathrm{Ra}$ is the armature resistance (In ohm)

$\mathrm{La}$ is the armature inductance (In Henry)

Tm is the mechanical torque developed (In Nm)

$\mathrm{Jm}$ is moment of inertia ( $\mathrm{In} \mathrm{kg} / \mathrm{m}^{2}$ )

$\mathrm{Bm}$ is friction coefficient of the motor ( $\mathrm{In} \mathrm{Nm} /(\mathrm{rad} / \mathrm{sec})$ )

$\omega$ is angular velocity (In $\mathrm{rad} / \mathrm{sec}$ )

The armature voltage equation is given by:

$$
\mathrm{Va}=\mathrm{Eb}+\mathrm{IaRa}+\mathrm{La}(\mathrm{dIa} / \mathrm{dt})
$$

Now the torque balance equation will be given by:

$$
\mathrm{Tm}=\mathrm{Jmd} \omega / \mathrm{dt}+\mathrm{Bm} \omega+\mathrm{TL}
$$

Where: TL is load torque in $\mathrm{Nm}$.

Friction in rotor of motor is very small (can be neglected), so $\mathrm{Bm}=0$

Therefore, new torque balance equation will be given by:

$$
\mathrm{Tm}=\mathrm{Jmd} \omega / \mathrm{dt}+\mathrm{TL}
$$

Taking field flux as $\Phi$ and Back EMF Constant as K. Equation for back emf of motor will be:

$$
\mathrm{Eb}=\mathrm{K} \Phi \omega
$$

Also, $\mathrm{Tm}=\mathrm{K} \Phi$ Ia-

Taking Laplace transform of the motor's armature voltage equation we get

$$
\begin{aligned}
& \mathrm{Ia}(\mathrm{s})=(\mathrm{Va}-\mathrm{K} \Phi \omega) / \mathrm{Ra}(1+\mathrm{LaS} / \mathrm{Ra})-- \\
& \omega(\mathrm{s})=(\mathrm{Tm}-\mathrm{TL}) / \mathrm{JS}=(\mathrm{K} \Phi \mathrm{Ia}-\mathrm{TL}) / \mathrm{JmS}
\end{aligned}
$$

(Armature Time Constant) $\mathrm{Ta}=\mathrm{La} / \mathrm{Ra}$

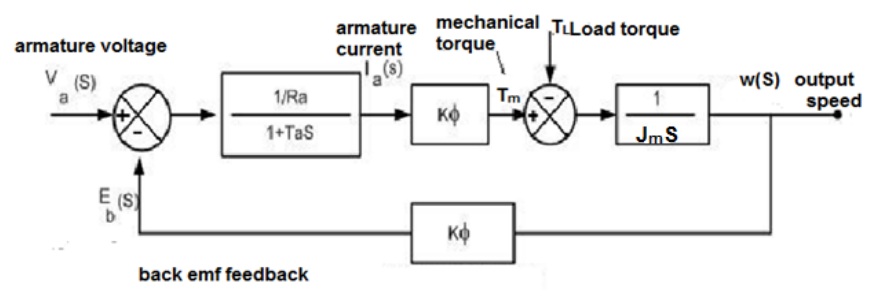

Figure 2: Block Model of Separately Excited DC Motor

\begin{tabular}{|c|c|}
\hline \multicolumn{2}{|c|}{ TABLE I. DC MOTOR PARAMETERS } \\
\hline Parameters & Value \\
\hline Armature resistance (Ra) & $0.5 \Omega$ \\
Armature inductance (La) & $0.02 \mathrm{H}$ \\
Armature voltage (Va) & $200 \mathrm{~V}$ \\
Mechanical inertia (jm) & $0.1 \mathrm{Kg} . \mathrm{m} 2$ \\
Friction coefficient (Bm) & $0.008 \mathrm{~N} \cdot \mathrm{m} / \mathrm{rad} / \mathrm{sec}$ \\
Back emf constant (k) & $1.25 \mathrm{~V} / \mathrm{rad} / \mathrm{sec}$ \\
Rated speed & $1500 \mathrm{r} . \mathrm{p} . \mathrm{m}$ \\
\hline
\end{tabular}

\section{FUZZY LOGIC CONTROLLER}

The fuzzy logic foundation is based on the simulation of people's opinions and perceptions to control any system. One of the methods to simplify complex systems is to tolerate to imprecision, vagueness and uncertainty up to some extent [10]. An expert operator develops flexible control mechanism using words like "suitable, not very suitable, high, little high, much and far too much that are frequently used words in people's life. Fuzzy logic control is constructed on these logical relationships. Fuzzy sets are used to show linguistic variables. Fuzzy Sets Theory is first introduced in 1965 by Zadeh to express and process fuzzy knowledge [11, 12]. There is a strong relationship between fuzzy logic and fuzzy set theory that is similar relationship between Boolean logic and classic set theory. Fig. 3 shows a basic FLC structure. 


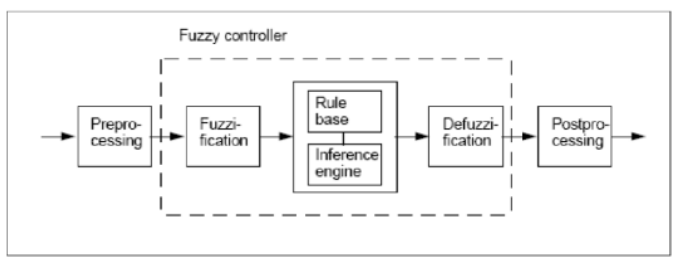

Figure 3: Structure of fuzzy logic controller

The input to the Self-tuning Fuzzy PID Controller are speed error "e(t)" and Change-in-speed error "de(t)". The input shown in figure are described by

$e(t)=w r(t)-w a(t)$

de $(\mathrm{t})=\mathrm{e}(\mathrm{t})-\mathrm{e}(\mathrm{t}-1)$

Using fuzzy control rules on-line, PID parameters "KP"," KI"," KD" are adjusted, which constitute a self-tuning fuzzy PID controller as shown in Figure4.

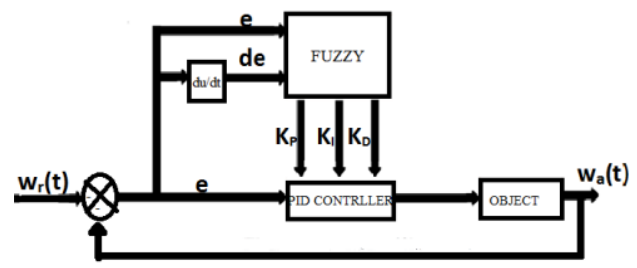

Figure 4: The structure of self-tuning fuzzy PID controller

PID parameters fuzzy self-tuning is to find the fuzzy relationship between the three parameters of PID and "e" and "de", and according to the principle of fuzzy control, to modify the three parameters in order to meet different requirements for control parameters when "e" and "de" are different, and to make the control object a good dynamic and static performance

In order to improve the performance of FLC, the rules and membership functions are adjusted. The membership functions are adjusted by making the area of membership functions near ZE region narrower to produce finer control resolution. On the other hand, making the area far from ZE region wider gives faster control response. Also the performance can be improved by changing the severity of rules [14]. An experiment to study the effect of rise time (Tr), maximum overshoot (Mp) and steady-state error (SSE) when varying KP, $\mathrm{KI}$ and KD was conducted. The results of the experiment were used to develop 25-rules for the FLC of KP, KI and $\mathrm{KD}$.

\subsection{Design Of Membership Function (MF)}

Input variables: Fuzzy sets of speed error (e) variable

Table 2: Membership function of speed error

\begin{tabular}{|c|l|l|c|}
\hline $\begin{array}{c}\text { Fuzzy set } \\
\text { (Label) }\end{array}$ & \multicolumn{1}{|c|}{ Description } & $\begin{array}{c}\text { Numerical } \\
\text { Range }\end{array}$ & $\begin{array}{c}\text { Shape of Membership } \\
\text { Function }\end{array}$ \\
\hline $\begin{array}{c}\text { Negative large } \\
\text { (NL) }\end{array}$ & $\begin{array}{l}\text { Large Speed } \\
\text { difference in negative } \\
\text { direction }\end{array}$ & $\begin{array}{l}-20 \text { to }-20 \\
-20 \text { to } 40\end{array}$ & Triangular \\
\hline $\begin{array}{c}\text { Negative small } \\
\text { (NS) }\end{array}$ & $\begin{array}{l}\text { Small Speed } \\
\text { difference in negative } \\
\text { direction }\end{array}$ & $\begin{array}{l}10 \text { to } 40 \\
40 \text { to } 100\end{array}$ & Triangular \\
\hline $\begin{array}{c}\text { Zero } \\
\text { (ZE) }\end{array}$ & $\begin{array}{l}\text { Speed difference is } \\
\text { zero }\end{array}$ & $\begin{array}{l}40 \text { to } 70 \\
70 \text { to } 100\end{array}$ & Triangular \\
\hline $\begin{array}{c}\text { Positive Small } \\
\text { (PS) }\end{array}$ & $\begin{array}{l}\text { Small Speed } \\
\text { difference in positive } \\
\text { direction }\end{array}$ & $\begin{array}{l}40 \text { to } 100 \\
100 \text { to } 130\end{array}$ & Triangular \\
\hline $\begin{array}{c}\text { Positive large } \\
\text { (PL) }\end{array}$ & $\begin{array}{l}\text { Large Speed } \\
\text { difference in positive } \\
\text { direction }\end{array}$ & 100 to 160 & \\
\hline
\end{tabular}




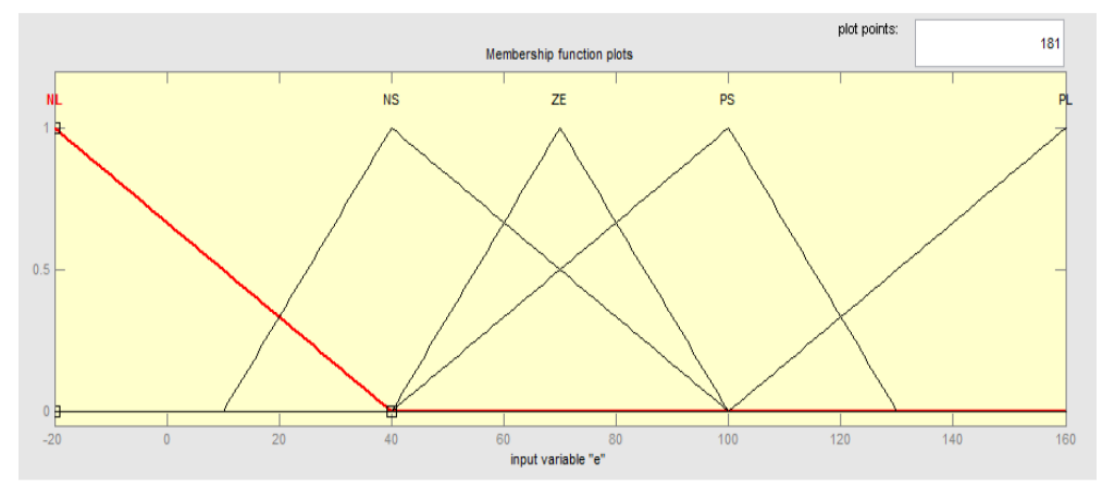

Figure 5: Membership function for input variable "e"

Table 3: Membership function of change in speed error.

\begin{tabular}{|c|l|l|c|}
\hline $\begin{array}{c}\text { Fuzzy set } \\
\text { (Label) }\end{array}$ & \multicolumn{1}{|c|}{ Description } & \multicolumn{1}{|c|}{$\begin{array}{c}\text { Numerical } \\
\text { Range }\end{array}$} & $\begin{array}{c}\text { Membership } \\
\text { Function }\end{array}$ \\
\hline $\begin{array}{c}\text { Negative large } \\
\text { (NL) }\end{array}$ & $\begin{array}{l}\text { Large error difference } \\
\text { in negative direction }\end{array}$ & $\begin{array}{l}-1300 \text { to }-1300 \\
-1300 \text { to }-800\end{array}$ & Triangular \\
\hline $\begin{array}{c}\text { Negative small } \\
\text { (NS) }\end{array}$ & $\begin{array}{l}\text { Small error } \\
\text { difference in negative } \\
\text { direction }\end{array}$ & $\begin{array}{l}-1050 \text { to }-800 \\
-800 \text { to }-300\end{array}$ & Triangular \\
\hline Zero & Error difference is & -800 to -550 & Triangular \\
(ZE) & zero & -550 to -300 & Triangular \\
\hline Positive Small & $\begin{array}{l}\text { Small error difference } \\
\text { ins) }\end{array}$ & -800 to -300 & \\
\hline Positive large & Large error difference & -300 to -50 & -300 to -300 \\
(PL) & in positive direction & -300 to 200 & \\
\hline
\end{tabular}

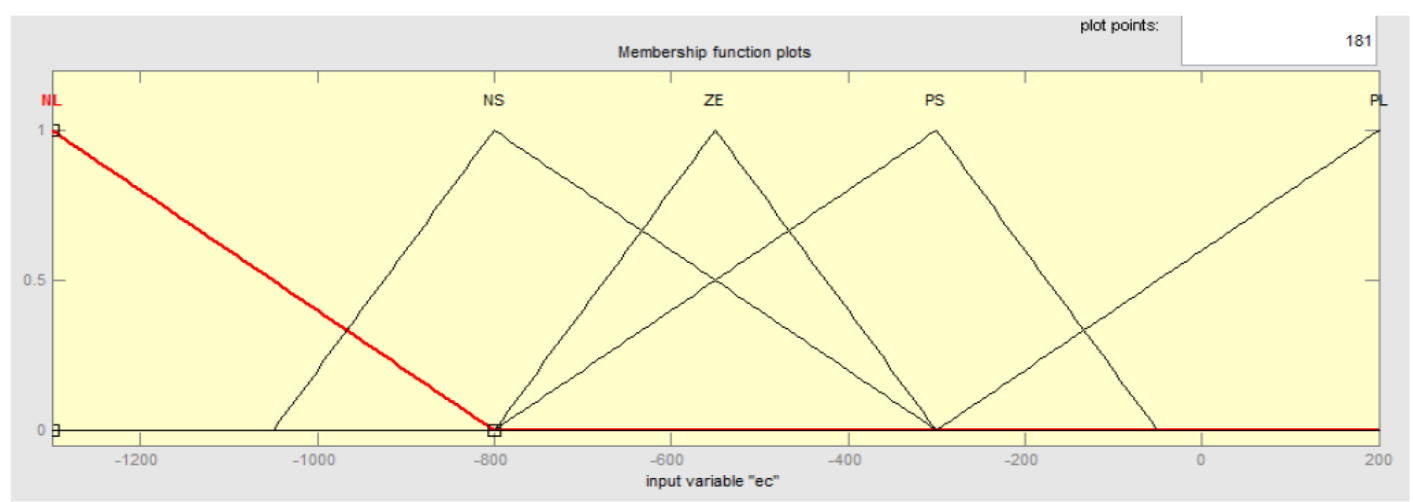

Figure6: Membership function for input variable "de" Output variable:

Table 4: Membership function proportional gain KP.

\begin{tabular}{|c|c|c|}
\hline $\begin{array}{l}\text { Fuzzy set } \\
\text { (Label) }\end{array}$ & Numerical Range & Membership function \\
\hline $\begin{array}{l}\text { Positive very small } \\
\text { (PVS) }\end{array}$ & $\begin{array}{l}0 \text { to } 0 \\
0 \text { to } 10\end{array}$ & Triangular \\
\hline $\begin{array}{l}\text { Positive Small } \\
\text { (PS) }\end{array}$ & $\begin{array}{l}0 \text { to } 5 \\
5 \text { to } 15\end{array}$ & Triangular \\
\hline $\begin{array}{l}\text { Positive Medium small } \\
\text { (PMS) }\end{array}$ & $\begin{array}{l}5 \text { to } 10 \\
10 \text { to } 20\end{array}$ & Triangular \\
\hline $\begin{array}{l}\text { Positive Medium } \\
\text { (PM) }\end{array}$ & $\begin{array}{l}10 \text { to } 15 \\
15 \text { to } 20\end{array}$ & Triangular \\
\hline $\begin{array}{l}\text { Positive Medium Large } \\
\text { (PML) }\end{array}$ & $\begin{array}{l}10 \text { to } 20 \\
20 \text { to } 25\end{array}$ & Triangular \\
\hline $\begin{array}{l}\text { Positive Large } \\
\text { (PL) }\end{array}$ & $\begin{array}{l}15 \text { to } 25 \\
25 \text { to } 30\end{array}$ & Triangular \\
\hline $\begin{array}{l}\text { Positive very Large } \\
\text { (PVL) }\end{array}$ & $\begin{array}{l}20 \text { to } 30 \\
30 \text { to } 30\end{array}$ & Triangular \\
\hline
\end{tabular}




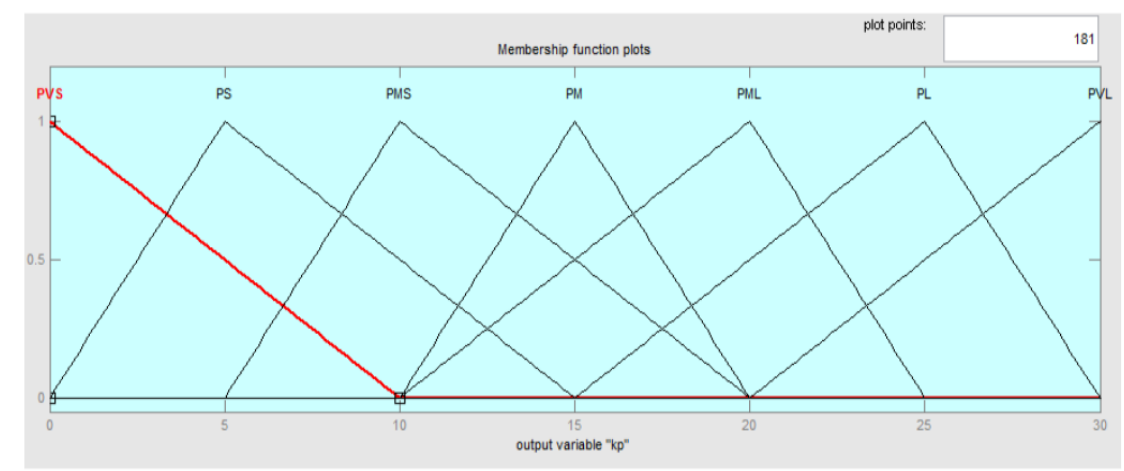

Figure 7: Membership function for output variable "KP"

Table 5: Membership function integral gain KI.

\begin{tabular}{|c|c|c|}
\hline $\begin{array}{c}\text { Fuzzy set } \\
\text { (Label) }\end{array}$ & Numerical Range & Membership function \\
\hline $\begin{array}{c}\text { Positive very small } \\
\text { (PVS) }\end{array}$ & 0 to 0 \\
0 to 20 & Triangular \\
\hline $\begin{array}{c}\text { Positive Small } \\
\text { (PS) }\end{array}$ & 0 to 10 & Triangular \\
\hline Positive Medium small & 10 to 30 & Triangular \\
(PMS) & 20 to 40 & Triangular \\
\hline Positive Medium & 20 to 30 & Triangular \\
(PM) & 30 to 40 & Triangular \\
\hline Positive Medium Large & 20 to 40 & \\
\hline (PML) & 40 to 50 & Triangular \\
\hline Positive Large & 30 to 50 & \\
\hline (PL) & 50 to 60 & 40 to 60 \\
\hline $\begin{array}{c}\text { Positive very Large } \\
\text { (PVL) }\end{array}$ & 60 to 60 & \\
\hline
\end{tabular}

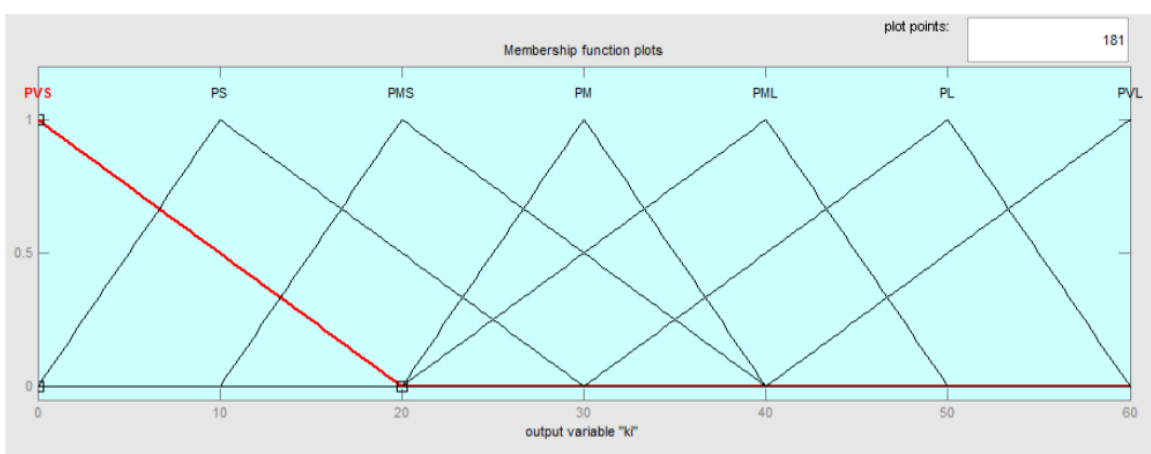

Figure 8: Membership function for output variable "KI"

Table 6: Membership function derivative gain KD.

\begin{tabular}{|c|c|c|}
\hline $\begin{array}{c}\text { Fuzzy set } \\
(\text { Label })\end{array}$ & Numerical Range & $\begin{array}{l}\text { Shape of Membership } \\
\text { function }\end{array}$ \\
\hline $\begin{array}{l}\text { Positive very small } \\
\text { (PVS) }\end{array}$ & $\begin{array}{l}0 \text { to } 0 \\
0 \text { to } 2\end{array}$ & Triangular \\
\hline $\begin{array}{c}\text { Positive Small } \\
\text { (PS) }\end{array}$ & $\begin{array}{l}0 \text { to } 1 \\
1 \text { to } 3\end{array}$ & Triangular \\
\hline $\begin{array}{l}\text { Positive Medium small } \\
\text { (PMS) }\end{array}$ & $\begin{array}{l}1 \text { to } 2 \\
2 \text { to } 4\end{array}$ & Triangular \\
\hline $\begin{array}{l}\text { Positive Medium } \\
(\mathrm{PM})\end{array}$ & $\begin{array}{l}2 \text { to } 3 \\
3 \text { to } 4\end{array}$ & Triangular \\
\hline $\begin{array}{l}\text { Positive Medium Large } \\
\text { (PML) }\end{array}$ & $\begin{array}{l}2 \text { to } 4 \\
4 \text { to } 5\end{array}$ & Triangular \\
\hline $\begin{array}{l}\text { Positive Large } \\
\text { (PL) }\end{array}$ & $\begin{array}{l}3 \text { to } 5 \\
5 \text { to } 6\end{array}$ & Triangular \\
\hline $\begin{array}{l}\text { Positive very Large } \\
\text { (PVL) }\end{array}$ & $\begin{array}{l}4 \text { to } 6 \\
6 \text { to } 6\end{array}$ & Triangular \\
\hline
\end{tabular}




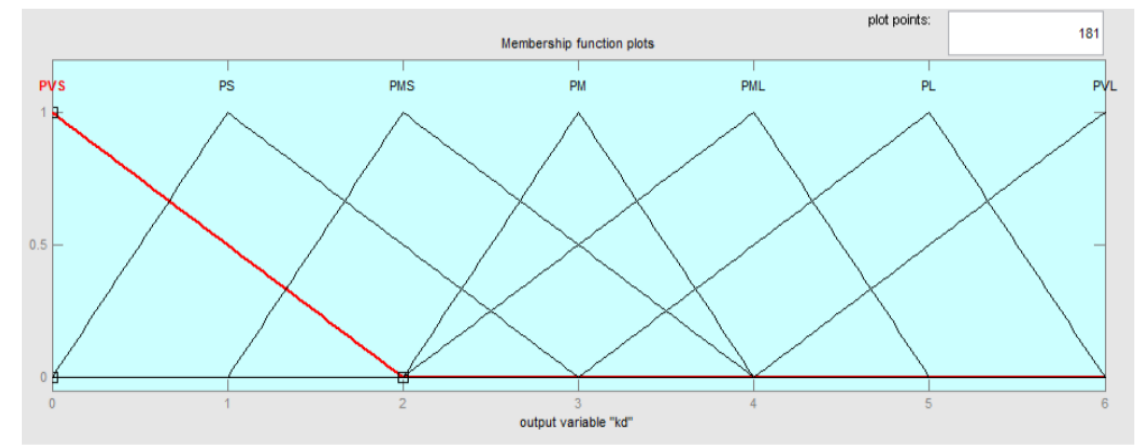

Figure 9: Membership function for output variable "KD

\subsection{Design Of Fuzzy Rules}

Table 7: Fuzzy rule table for KP

\begin{tabular}{|c|c|c|c|c|c|}
\hline de/e & NL & NS & ZE & PS & PL \\
\hline NL & PVL & PVL & PVL & PVL & PVL \\
\hline NS & PML & PML & PML & PL & PVL \\
\hline ZE & PVS & PVS & PS & PMS & PMS \\
\hline PS & PML & PML & PML & PL & PVL \\
\hline PL & PVL & PVL & PVL & PVL & PVL \\
\hline
\end{tabular}

Table 8: Fuzzy rule table for KI

\begin{tabular}{|c|c|c|c|c|c|}
\hline de/e & NL & NS & ZE & PS & PL \\
\hline NL & PM & PM & PM & PM & PM \\
\hline NS & PMS & PMS & PMS & PMS & PMS \\
\hline ZE & PS & PS & PVS & PS & PS \\
\hline PS & PMS & PMS & PMS & PMS & PMS \\
\hline PL & PM & PM & PM & PM & PM \\
\hline
\end{tabular}

Table 9: Fuzzy rule table for KD

\begin{tabular}{|c|c|c|c|c|c|}
\hline de/e & NL & NS & ZE & PS & PL \\
\hline NL & PVS & PMS & PM & PL & PVL \\
\hline NS & PMS & PML & PL & PVL & PVL \\
\hline ZE & PM & PL & PL & PVL & PVL \\
\hline PS & PML & PVL & PVL & PVL & PVL \\
\hline PL & PVL & PVL & PVL & PVL & PVL \\
\hline
\end{tabular}

IV. Matlab Simulation

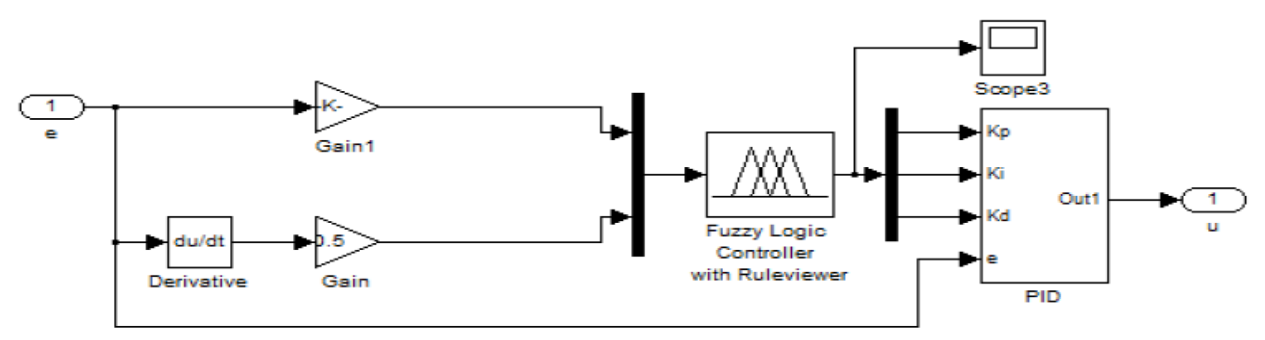

FIGURE 11: SIMULINK MODEL OF FUZZY-PID CONTROLLER 


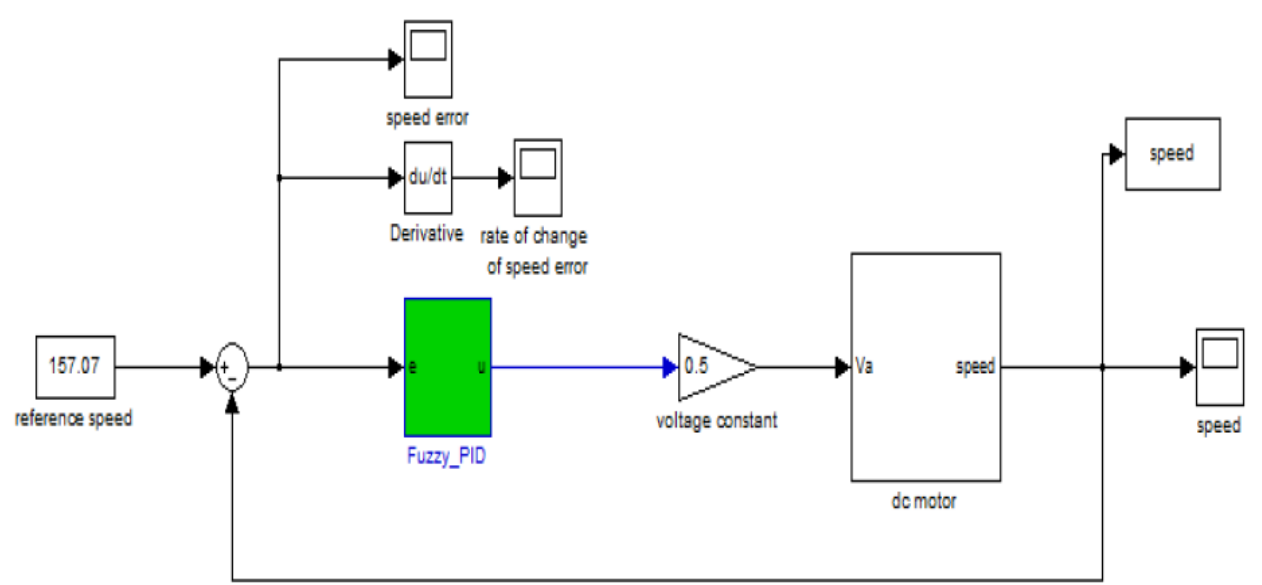

Figure 10: Simulink Model for Speed Control of Separately Excited DC motor using self tuned fuzzy PID controller

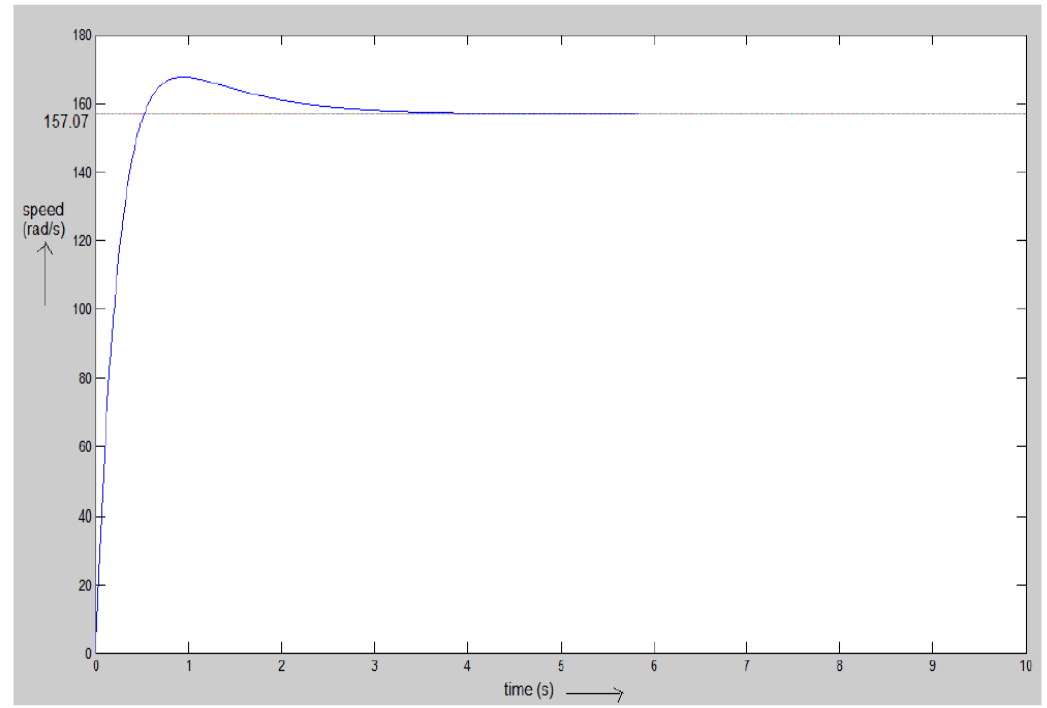

FIGURE 12: SPEED VS TIME RESPONSE OF FUZZY TUNED PID CONTROLLED DC MOTOR

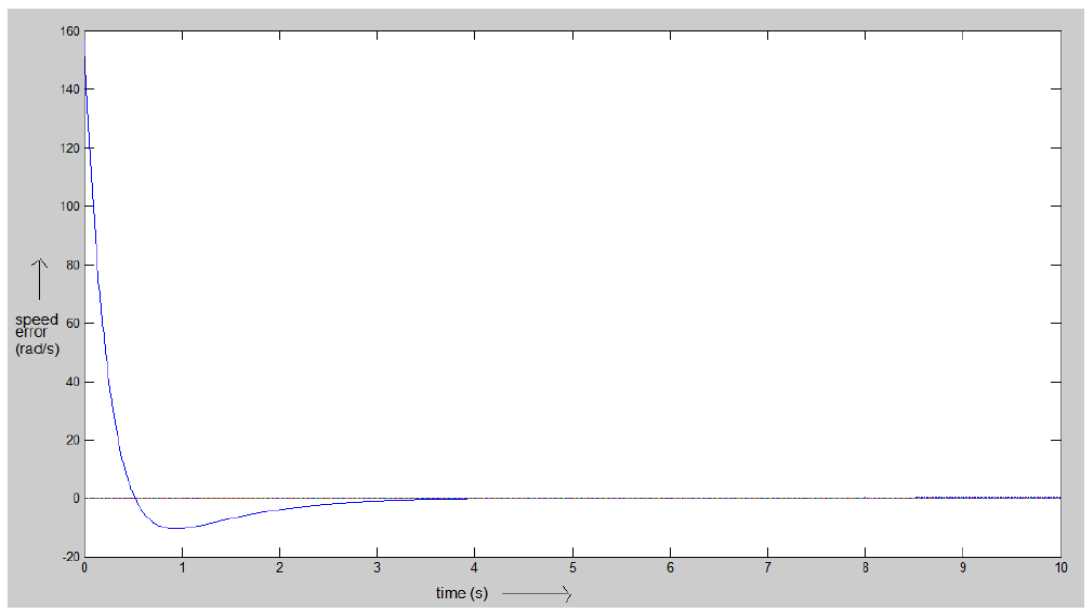

Figure13: Error Vs time response of fuzzy tuned PID controlled DC motor 


\section{Conclusion}

Comparison between self tuned fuzzy PID and conventional PID controller Self-tuned tuning PID controller is less compared to conventional PID controller.

The three parameters "KP", "KI", "KD" of conventional PID control need to be constantly adjust adjusted online in order to achieve better control performance. Fuzzy self-tuning PID parameters controller can automatically adjust PID parameters in accordance with the speed error and the rate of speed error-change, so it has better self-adaptive capacity fuzzy PID parameter controller has smaller overshoot and less rising and settling time than conventional PID controller and has better dynamic response properties and steady-state properties. Steady state error in case of self tuned fuzzy PID is less compared to conventional PID controller.

The fuzzy controller adjusted the proportional, integral and derivate (KP, KI, KD) gains of the PID controller according to speed error and change in speed error .From the simulation results it is concluded that ,compared with the conventional PID controller, self-tuning PID controller has a better performance in both transient and steady state response. The self tuning FLC has better dynamic response curve, shorter response time, small overshoot, small steady state error (SSE), high steady precision compared to the conventional PID controller.

\section{Reference}

[1] B.J. Chalmers, "Influence of saturation in brushless permanent magnet drives." IEE proc. B, Electr.Power Appl, vol.139, no.1, 1992.

[2] C.T. Johnson and R.D. Lorenz, "Experimental identification of friction and its compensation in precise, position controlled mechanism.” IEEE Trans. Ind ,Applicat, vol.28, no.6, 1992

[3] J. Zhang, N. Wang and S. Wang, "A developed method of tuning PID controllers with fuzzy rules for integrating process," Proceedings of the American Control Conference, Boston, 2004, pp. 1109-1114.

[4] K.H. Ang, G. Chong and Y. Li, "PID control system analysis, design and technology," IEEE transaction on Control System Technology, Vol.13, No.4, 2005, pp. 559-576

[5] H.X.Li and S.K.Tso, "Quantitative design and analysis of Fuzzy Proportional-Integral-Derivative Control- a Step towards Auto tuning", International journal of system science, Vol.31, No.5, 2000, pp.545-553.

[6] Thana Pattaradej, Guanrong Chen and PitikhateSooraksa, "Design and Implementation of Fuzzy PID Control of a bicycle robot", Integrated computer-aided engineering, Vol.9, No.4, 2002.

[7] Weiming Tang, Guanrong Chen and Rongde Lu, “A Modified Fuzzy PI Controller for a Flexible-joint Robot Arm with Uncertainties", Fuzzy Set and System, 118 (2001) 109-119.

[8] PavolFedor, Daniela Perduková, “A Simple Fuzzy Controller Structure,”ActaElectrotechnica ET Informatica No. 4, Vol. 5, 2005

[9] Maher M.F. Algreer andYhyaR.M.Kuraz, "Design Fuzzy Self Tuning of PID Controller for Chopper-Fed DC Motor drive." Kuraz

[10] J.Klir. George, Yuan, Bo. "Furry Sets and Fuzzy Logic- Theory and Applications"

[11] L. A. Zadeh, "Fuzzy Sets“Informal Control, vol.8, pp 338- 353, 1965

[12] L. A. Zadeh, 'Outline of a new approach to the analysis Complex systems and decision processes" IEEE Trans. Syst.Man Cybem, vol. SMC-3, pp. 2844, I973

[13] Y. Tipsuwan, Y. Chow, "Fuzzy Logic Micmcontroller Implementation for DC Motor Speed Control". IEEE. 1999

[14] M.Chow and A. Menozzi ,"on the comparison of emerging and conventional techniques for DC motor control" proc.IECON ,PP.1008-1013, 1992.

[15] Ogata, K., Modern Control Engineering. Englewood Cliffs, NJ: Prentice Hall, 2001

[16] P.S Bhimbhra, electrical machinery, New Delhi, Khanna Publishers. 